\title{
Percepção dos auxiliares odontológicos na clínica ortodôntica quanto aos seus limites de atuação profissional
}

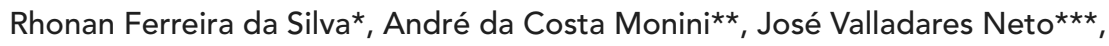
Luiz Francesquini Júnior ${ }^{\star \star \star \star}$, Eduardo Daruge Júnior ${ }^{\star \star \star \star}$

\begin{abstract}
Resumo
Introdução: numa época em que o mercado odontológico exige que os serviços prestados possuam qualidade diferenciada, a utilização adequada de profissionais auxiliares constitui uma ferramenta importantíssima para se obter aumento de produtividade no consultório. Para tanto, a correta utilização dessa ferramenta exige que a equipe auxiliar seja tecnicamente capacitada e envolvida num ambiente onde as funções delegadas estejam fundamentadas nos preceitos éticos e nas bases legais que regem a profissão. Objetivo: identificação do perfil técnico da equipe auxiliar, analisando-se a percepção destes profissionais quanto ao seu papel nas atividades pertinentes à clínica ortodôntica, com base na legislação vigente. Metodologia: o presente levantamento foi desenvolvido com base num questionário aplicado a todos os profissionais que auxiliam diretamente os ortodontistas regularmente inscritos no CRO-GO, que atendem nas cidades de Goiânia e Aparecida de Goiânia (GO), no período de maio a julho de 2003. Resultados e Conclusões: verificou-se que diversos procedimentos não estabelecidos nas normas que regem a delegação de funções em Odontologia estão sendo executados pela equipe auxiliar, demonstrando que o conteúdo dessa legislação está sendo ignorado ou descumprido.
\end{abstract}

Palavras-chave: Auxiliares de Odontologia. Ética. Odontologia Legal. Ortodontia.

\section{INTRODUÇÃO}

A utilização de mão de obra auxiliar na clínica odontológica tem se mostrado uma necessidade para a otimização da produtividade , $, 5,6,7,9$. Dentre as várias categorias odontológicas auxiliares reconhecidas pelo Conselho Federal de Odontologia (CFO), o Auxiliar de Consultório Dentário (ACD) e o Técnico em Higiene Dental (THD) são aquelas que normalmente são utilizadas tanto por clínicos gerais quanto por especialistas. No consultório odontológico, além do ACD e do THD, normalmente existe a figura da secretária, cuja função é exercida por quem auxilia o profissional da Odontologia em questões administrativas (recepção, agenda de pacientes, correspondências, dentre outras funções) e que não possui curso de

\footnotetext{
* Doutorando em Biologia Bucodental/Anatomia FOP-UNICAMP. Professor de Odontologia Legal UNIP-GO.

** Mestre e doutorando em Ortodontia UNESP/Araraquara.

*** Mestre em Morfologia pelo ICB-UFG. Professor assistente de Ortodontia Preventiva FO-UFG.

$\star \star \star \star$ Professores doutores em Odontologia Legal FOP/UNICAMP.
} 
formação ou habilitação legal para exercer as atribuições de ACD ou THD.

As categorias de ACD e THD foram inicialmente regulamentadas em 1975, tendo o seu exercício profissional disciplinado a partir de $1984^{8}$. Atualmente, as atribuições dessas duas categorias estão estabelecidas na Consolidação das Normas para Procedimentos nos Conselhos de Odontologia, documento aprovado pela Resolução CFO 063/2005². Nessa norma, estão enumeradas todas as funções que podem ser delegadas pelo cirurgião-dentista à sua equipe auxiliar, sendo que a maioria delas está relacionada com o auxílio de atos praticados na clínica geral, promoção de saúde (prevenção) e desempenho de funções administrativas do consultório odontológico.

$\mathrm{Na}$ clínica ortodôntica, especificamente, constitui prática frequente a presença de dois ou mais "equipos", com presença de vários auxiliares odontológicos ${ }^{1,10}$. Nesta relação interprofissional, envolvendo ortodontistas e auxiliares, exige-se que todos possuam um comportamento ético tanto na execução quanto na delegação de procedimentos odontológicos, atentando para o conteúdo do Código de Ética Odontológica (CEO) vigente 3 .

Sabendo que os auxiliares odontológicos podem, e devem, ser inseridos na rotina ortodôntica, respeitando-se a legislação vigente, o presente trabalho tem como objetivo investigar o perfil da formação profissional da equipe auxiliar odontológica que atua junto aos ortodontistas das cidades de Goiânia e Aparecida de Goiânia, e identificar o nível de conhecimento que os integrantes dessa equipe possuem sobre os seus limites de atuação profissional, ressaltando as possíveis repercussões éticas e legais diante de uma situação de extrapolação de funções no exercício da Odontologia.

\section{MATERIAL E MÉTODOS}

Para a realização do presente estudo, elaborou-se um questionário contendo perguntas estruturadas, as quais sinalizam aspectos inerentes à formação profissional e atualização dos conhecimentos da equipe auxiliar odontológica (secretária, ACD e THD) que atua junto aos especialistas em Ortodontia e Ortopedia Facial, devidamente inscritos no Conselho Regional de Odontologia de Goiás (CRO-GO), das cidades de Goiânia e Aparecida de Goiânia, ambas sitiadas no estado de Goiás, no período de maio a julho de 2003. Também foram questionados quais os procedimentos que os integrantes da equipe auxiliar normalmente executam, ou estão aptos a executar, durante o atendimento ortodôntico. Algumas questões eram compostas por múltiplas alternativas, podendo os profissionais assinalar mais de uma. Os questionários foram entregues pessoalmente aos auxiliares dos ortodontistas, sendo recolhidos posteriormente, em data agendada. Nesse questionário, foi assegurada a cada participante, em número total de 232, a confidencialidade das informações prestadas e a voluntariedade da participação no trabalho, além do uso exclusivo para fins de pesquisa, por meio de um Termo de Consentimento Livre e Esclarecido. A presente pesquisa foi devidamente aprovada pelo Comitê de Ética em Pesquisa da Faculdade de Odontologia de Piracicaba - UNICAMP, sob o número do protocolo 137/2003. Os dados obtidos nos questionários foram informatizados, utilizando-se planilhas do programa Microsoft Excel 2000 (Microsoft, EUA), obtendo-se as frequências das respostas, cujos resultados foram analisados por meio de estatística descritiva.

\section{RESULTADOS}

Foram entrevistados 232 profissionais auxiliares que atuavam junto a $88,4 \%$ (84) do total de ortodontistas que se apresentavam devidamente inscritos no CRO-GO. Dentre esses ortodontistas, apenas 4,8\% (4) não utilizavam pessoal auxiliar.

Dos 232 questionários aplicados aos auxiliares dos ortodontistas, $120(51,7 \%)$ foram devolvidos, cujo levantamento constatou que a totalidade da amostra era composta por profissionais do gênero feminino. Quando analisado o grau de escolaridade 
das entrevistadas, constatou-se que $66,7 \%$ possuíam o ensino médio completo, $14,1 \%$ nível superior incompleto, $12,5 \%$ nível médio incompleto, 4,2\% superior completo e as demais possuíam apenas o ensino fundamental.

Do total pesquisado 43,3\% fizeram curso de formação específico para ACD, 10,8\% para THD e 48,4\% não possuíam curso de formação para ACD ou THD. Ressalta-se que 2,5\% das profissionais possuíam mais de um curso de formação específica. Do total da amostra, 80\% (96) receberam treinamento específico para trabalho em consultório odontológico pelo ortodontista. Das 120 profissionais entrevistadas, $61,7 \%$ possuíam inscrição no CRO-GO.

Quando questionado onde estava presente a legislação que estabelece quais as funções que podem ser delegadas à equipe auxiliar, $68,4 \%$ relataram não saber, $20 \%$ citaram a resolução $\mathrm{CFO}$ 185/93 (que corresponde atualmente à Resolução CFO 063/2005²), 10,8\% citaram o Código de Ética Odontológica ${ }^{3}$ e $0,8 \%$ apontou outro documento.

Sobre o questionamento referente à frequência da participação das auxiliares em cursos de atualização das suas respectivas áreas, constatouse que $50,8 \%$ não participavam de nenhum tipo de curso, 26,7\% participavam anualmente, 13,3\% bianualmente e as demais relataram participar em outra periodicidade. Do total de auxiliares, 53,3\% relataram que o ortodontista está presente fisicamente quando os procedimentos são executados diretamente na boca do paciente, $31,7 \%$ não e $15 \%$ está presente eventualmente.

Dentre os diversos procedimentos que os profissionais auxiliares executavam ou se consideravam legalmente habilitados a executar, os dados representados nas tabelas 1 e 2 estão relacionados com as atribuições permitidas pela Resolução CFO 063/2005². Na tabela 3, foram relacionados outros procedimentos, comuns da rotina de tratamento ortodôntico, e que não estão relacionados na norma supracitada.

\begin{tabular}{|c|c|c|}
\hline \multirow{2}{*}{$\begin{array}{c}\text { FUNÇÕES EXECUTADAS } \\
\text { OU PERCEBIDAS COMO POSSIVEIS DE } \\
\text { EXECUÇÃ̃O }\end{array}$} & \multicolumn{2}{|c|}{ FREQUÊNCIA } \\
\hline & absoluta & relativa $(\%)$ \\
\hline realizar teste de vitalidade pulpar & 4 & 3,3 \\
\hline responder pela administração da clínica & 13 & 10,8 \\
\hline $\begin{array}{l}\text { fazer a tomada e revelar radiografias } \\
\text { intrabucais }\end{array}$ & 15 & 12,5 \\
\hline $\begin{array}{l}\text { realizar a remoção de indutos, placas e } \\
\text { cálculos supragengivais }\end{array}$ & 19 & 15,8 \\
\hline $\begin{array}{l}\text { participar do treinamento de Auxiliar de } \\
\text { Consultório Dentário (ACD) }\end{array}$ & 61 & 50,8 \\
\hline $\begin{array}{l}\text { fazer a demonstração da técnica de } \\
\text { escovação }\end{array}$ & 83 & 69,2 \\
\hline preparar moldeiras & 94 & 78,3 \\
\hline confeccionar modelos & 96 & 80 \\
\hline
\end{tabular}

TABELA 2 - Funções permitidas pela legislação vigente (Resolução CFO $063 / 2005^{2}$ ), de competência do $A C D$, relatadas como sendo executadas ou possíveis de execução pela amostra entrevistada $(n=120)$.

\begin{tabular}{|c|c|c|}
\hline \multirow{2}{*}{$\begin{array}{l}\text { FUNÇÕES EXECUTADAS OU } \\
\text { PERCEBIDAS COMO POSSÍVEIS DE } \\
\text { EXECUÇÃ̃O }\end{array}$} & \multicolumn{2}{|c|}{ FREQUÊNCIA } \\
\hline & absoluta & relativa (\%) \\
\hline $\begin{array}{l}\text { revelar e montar radiografias } \\
\text { intrabucais }\end{array}$ & 21 & 17,5 \\
\hline controlar o movimento financeiro & 44 & 36,7 \\
\hline $\begin{array}{l}\text { aplicar métodos preventivos para } \\
\text { controle da cárie dentária }\end{array}$ & 49 & 40,8 \\
\hline preencher e marcar fichas clínicas & 69 & 57,5 \\
\hline selecionar moldeiras & 80 & 66,7 \\
\hline $\begin{array}{l}\text { instrumentar o cirurgião-dentista e o } \\
\text { THD junto à cadeira operatória }\end{array}$ & 80 & 66,7 \\
\hline orientar o paciente sobre higiene bucal & 92 & 76,7 \\
\hline $\begin{array}{l}\text { proceder a conservação e a manuten- } \\
\text { ção do equipamento odontológico }\end{array}$ & 92 & 76,7 \\
\hline $\begin{array}{l}\text { manipular materiais } \\
\text { de uso odontológico }\end{array}$ & 94 & 78,3 \\
\hline manter em ordem 0 arquivo e o fichário & 95 & 79,2 \\
\hline confeccionar modelos de gesso & 96 & 80 \\
\hline marcar consultas & 99 & 82,5 \\
\hline preparar o paciente para 0 atendimento & 110 & 91,7 \\
\hline auxiliar no atendimento ao paciente & 110 & 91,7 \\
\hline
\end{tabular}


TABELA 3 - Funções não estabelecidas na Resolução CFO 063/2005² relatadas como sendo executadas ou possíveis de execução pela amostra entrevistada $(n=120)$.

\begin{tabular}{|c|c|c|}
\hline \multirow{2}{*}{$\begin{array}{l}\text { FUNÇÕES EXECUTADAS OU } \\
\text { PERCEBIDAS COMO POSSIVVEIS DE } \\
\text { EXECUÇÃOO }\end{array}$} & \multicolumn{2}{|c|}{ FREQUÊNCIA } \\
\hline & absoluta & relativa (\%) \\
\hline colagem direta de braquetes & 11 & 9,2 \\
\hline $\begin{array}{l}\text { ativação de grampos e/ou molas de } \\
\text { aparelhos ortodônticos }\end{array}$ & 12 & 10 \\
\hline colagem da contenção fixa & 25 & 20,8 \\
\hline remoção do aparelho ortodôntico & 25 & 20,8 \\
\hline $\begin{array}{l}\text { remoção da resina que fica aderida } \\
\text { nos dentes após a retirada do } \\
\text { aparelho ortodôntico }\end{array}$ & 28 & 23,3 \\
\hline $\begin{array}{c}\text { adaptação (calcar) e/ou cimentar } \\
\text { de bandas ortodônticas }\end{array}$ & 32 & 26,7 \\
\hline trocar fios ortodônticos & 40 & 33,3 \\
\hline realização de moldagens de estudo & 43 & 35,8 \\
\hline $\begin{array}{l}\text { retirada ou colocação } \\
\text { de alastic/amarrilhos }\end{array}$ & 64 & 53,3 \\
\hline $\begin{array}{l}\text { colocação de borrachas para a } \\
\text { separação de dentes }\end{array}$ & 76 & 63,3 \\
\hline
\end{tabular}

\section{DISCUSSÃO}

A Odontologia presencia um momento em que o mercado de trabalho apresenta-se repleto de profissionais atuando nos grandes centros urbanos, tornando-se imperioso que o tempo e os investimentos destinados à prática odontológica sejam aproveitados ao máximo, sem perda da qualidade, para a sobrevivência da atividade econômica. Uma das formas de obter o aumento da produtividade do consultório é a inserção da equipe auxiliar, otimizando o tempo do cirurgião-dentista e reduzindo o custo da hora trabalhada. Diante da necessidade de se utilizar os auxiliares na Odontologia, e mais especificamente na Ortodontia, constatou-se que $95,2 \%$ (80) dos ortodontistas que tiveram seus auxiliares entrevistados empregavam algum tipo de profissional auxiliar, totalizando 232 dentre as profissões de secretária, ACD ou THD.

Analisando-se o perfil de formação técnica dos profissionais entrevistados que devolveram os questionários devidamente respondidos (120), constatou-se que a maioria possuía o ensino médio completo $(66,7 \%)$ e praticamente a metade $(48,4 \%)$ não possuía curso de formação específico para ACD ou THD. A falta de capacitação desses profissionais, por meio de cursos oferecidos por escolas de formação de auxiliares de Odontologia, reflete diretamente no número de profissionais auxiliares em situação regular junto ao $\mathrm{CRO}-\mathrm{GO}$, onde apenas $61,7 \%$ destes relataram estar devidamente inscritos. Esse fato deve ser observado com atenção pelos ortodontistas e demais cirurgiõesdentistas, pois constitui infração ética utilizar-se de serviços prestados por profissionais não habilitados legalmente ou por profissionais da área odontológica não regularmente inscritos no CRO de sua jurisdição, conforme estabelece o inciso IX do artigo $9^{\circ}$ do Código de Ética Odontológica (CEO) 3 .

Por outro lado, é sabido que não existem muitas escolas técnicas que propiciam a capacitação de profissionais auxiliares e, como o tratamento odontológico exige que todos os profissionais envolvidos estejam tecnicamente preparados, uma das saídas buscadas pelos cirurgiões-dentistas é o treinamento oferecido dentro do consultório. Esse fato foi observado no presente trabalho, onde $80 \%$ das entrevistadas relataram ter recebido treinamento específico pelos ortodontistas. Entretanto, a atualização técnica da equipe auxiliar não pode ficar restrita aos conhecimentos que são repassados pelos ortodontistas, pois se observou que praticamente a metade da amostra $(50,8 \%)$ não frequentava nenhum tipo de curso em sua área. A reciclagem e o aperfeiçoamento dos auxiliares devem ser constantes tanto para o ortodontista quanto para os auxiliares, visando aumentar a eficiência profissional, o retorno financeiro e a qualidade do tratamento oferecido à população. Além disso, a atualização dos conhecimentos é um dever ético dos profissionais da Odontologia, conforme estabelece o inciso IV do artigo $5^{\circ}$ do $\mathrm{CEO}^{3}$.

Ainda sobre o tema atualização de conhecimentos e sua importância no exercício da Odontologia, verificou-se que apenas 20\% da amostra indicaram 
corretamente a legislação que estabelece as atribuições específicas do ACD, THD e demais membros da equipe odontológica. Sabendo que essas atribuições estão atualmente estabelecidas na legislação aprovada pela Resolução CFO 063/2005² (que revogou a antiga norma relacionada à delegação de funções na Odontologia - Resolução CFO 185/93), o desconhecimento da mesma propicia que os profissionais da equipe auxiliar sejam subaproveitados ou extrapolem seus limites de atuação.

A análise dos dados obtidos no presente trabalho revelou que ambas as situações estavam configuradas. O subaproveitamento foi confirmado pelos dados presentes nas tabelas 1 e 2 , principalmente relacionado ao desconhecimento da possibilidade do THD responder pela administração da clínica $(10,8 \%)$ ou fazer a tomada e revelar radiografias intrabucais $(12,5 \%)$, e da possibilidade do ACD revelar e montar radiografias intrabucais $(17,5 \%)$ e aplicar métodos preventivos para controle da cárie dentária (40,8\%).

O extrapolamento de função foi constatado nos dados presentes na tabela 3, que aponta as funções não permitidas pela legislação vigente e que foram entendidas como permitidas ou possíveis de serem executadas pela equipe auxiliar. A colocação de borrachas para a separação de dentes, a retirada ou colocação de alastic/amarrilhos e a realização de moldagens de estudo foram as atribuições relatadas por $63,3 \%, 53,3 \%$ e $35,8 \%$ da amostra, respectivamente. Esses procedimentos também foram os mais delegados por $65,5 \%, 42,8 \%$ e $46,4 \%$ dos 84 ortodontistas entrevistados no trabalho de Silva et al. ${ }^{10}$, evidenciando que tanto ortodontistas quanto auxiliares desconhecem ou ignoram as funções que podem ser delegadas à equipe auxiliar. De acordo com a legislação vigente, os procedimentos listados na tabela 3 constituiriam atos privativos do cirurgião-dentista e, portanto, não poderiam ser delegados aos membros da equipe auxiliar. $\mathrm{O}$ descumprimento dessa legislação, por parte dos ortodontistas, é justificado sob alegação de que a Ortodontia não foi beneficiada ao se elaborar as atribuições da equipe auxiliar odontológica e que a sobrevivência econômica do consultório depende da maior colaboração dos auxiliares ${ }^{1}$.

Outra situação que fere a legislação vigente está relacionada ao fato de que o ortodontista não estaria presente $(31,7 \%)$ ou eventualmente estaria fisicamente presente (15\%) no ambiente quando são executados os procedimentos diretamente na boca do paciente pelas auxiliares. De acordo com o estabelecido na Resolução CFO 063/2005, é imprescindivel a presença física do cirurgião-dentista durante a realização dos atos delegados à equipe auxiliar $^{2}$. Atitudes dessa natureza configuram o exercício ilegal da Odontologia, com possibilidade de sanções nas áreas ética e penal para o profissional auxiliar, por infringir o inciso IV do artigo $9^{\circ}$ do $\mathrm{CEO}^{3}$ e artigo 282 do Código Penal Brasileiro ${ }^{11}$, respectivamente. Sanções éticas também podem ser aplicadas ao ortodontista, por delegar funções que configuram a extrapolação de função, inclusive podendo ser consideradas de manifesta gravidade, de acordo com o estabelecido no inciso II do artigo 42 do $\mathrm{CEO}^{3}$.

O caminho para se tentar amenizar essa situação de extrapolação de funções durante a execução das diversas etapas que compõem o tratamento ortodôntico é, fundamentalmente, conscientizar os profissionais da área odontológica sobre a importância de se respeitar a legislação vigente. Entretanto, caso a categoria odontológica entenda que determinados atos específicos do tratamento ortodôntico podem ser delegados à equipe auxiliar, por serem considerados reversíveis ou por não oferecerem riscos à saúde do paciente, que seja feita uma revisão prudente das normas vigentes, regulamentando a execução dos referidos procedimentos ${ }^{10}$.

\section{CONCLUSÕES}

A partir dos dados obtidos e de acordo com a metodologia empregada, é lícito concluir que:

- A grande maioria $(95,2 \%)$ dos ortodontistas utiliza pessoal auxiliar. Os auxiliares pertencem, 
em sua totalidade, ao gênero feminino e possuem formação de ensino médio completo em $66,7 \%$ dos casos.

- Menos da metade $(48,4 \%)$ dos auxiliares não possuía curso de formação específica na área odontológica para ACD ou THD, 61,7\% possuíam inscrição junto ao CRO-GO, a maioria (80\%) recebe treinamento do ortodontista e 50,8\% não frequentam cursos na sua área.

- Apenas 20\% dos auxiliares entrevistados in- dicaram corretamente onde está presente a legislação que regulamenta as atribuições da equipe auxiliar odontológica.

- Diversos procedimentos relacionados ao tratamento ortodôntico, não permitidos pela legislação vigente, estão sendo executados ou percebidos como possíveis de execução pela equipe auxiliar.

\title{
Dental assistant's awareness of their professional limits in orthodontic treatment
}

\begin{abstract}
Introduction: nowadays the odontological market demands treatments with a distinguished quality and the proper use of dental assistants represents an important tool to increase productivity in dental offices. In order to do so, those professionals must be technically capable and involved with the job, following their tasks based on ethics and legal requirements of dental professions. Aim: to identify the assistant team technical profile, analyzing their awareness concerning their legal prerogatives in orthodontic treatment. Methods: the present paper was developed upon a questionnaire that was answered by all dental assistants legally registered in the Goiás State Dental Board (CRO-GO) and applied in the cities of Goiânia and Aparecida de Goiânia/GO - Brazil. The research was conducted from May to June, 2003. Results and Conclusions: it was verified that several procedures that were not legally defined as assistant team tasks were being performed by those professionals. This results shows that Dentistry's professional laws have been either ignored or not followed.
\end{abstract}

Keywords: Dental assistants. Ethics. Forensic Dentistry. Orthodontics.

\section{REFERÊNCIAS}

1. BARROS, O. B. Auxiliares em Ortodontia. Rev. Clin. Ortodon. Dental Press, Maringá, v. 4, n. 2, p. 41-45, abr./maio 2005.

2. BRASIL. Conselho Federal de Odontologia. Consolidação das normas para procedimentos nos conselhos de Odontologia. Aprovado pela Resolução CFO n 63. Rio de Janeiro, 2005. Disponível em: <http://www.cfo.org.br>. Acesso em: 10 jan. 2007.

3. BRASIL. Conselho Federal de Odontologia. Código de ética odontológica. Aprovado pela Resolução CFO n 42 . Rio de Janeiro. 2003. Disponivel em: <http://www.cfo.org.br>. Acesso em: 10 jan. 2007.

4. ELEUTÉRIO, D.; SILVA FILHO, F. P. M. Freqüência da utilização da auxiliar odontológica na atividade clínica do cirurgiãodentista. Rev. Assoc. Paul. Cir. Dent., São Paulo, v. 35, n. 2, p. 118-124, mar./abr. 1981.

5. GARCIA, P. P. N. S.; TERENCE, R. L.; SOUZA, A. C. Avaliação de cirurgiões-dentistas quanto ao uso de pessoal auxiliar na organização do atendimento clínico. Rev. Odontol. UNESP, Araraquara, v. 33, n. 1, p. 25-32, jan./mar. 2004.

6. PIMENTA, A. Dentista X THD. Rev. Assoc. Paul. Cir. Dent., São Paulo, v. 48, n. 6, p. 1512-1522, nov./dez. 1994.

7. SALIBA, T. A.; ELEUTÉRIO, D.; SALIBA, C. A.; MOIMAZ, S. A. S. Trabalho odontológico auxiliado em serviços públicos e particulares. RPG: Rev. Pós-Grad., São Paulo, v. 5, n. 3, p. 171-176, jul./set. 1998.
8. SBRAVATI, R. S.; MENEGHIM, M. C.; PEREIRA, A. C. THD no mercado de trabalho: uma realidade? ROBRAC, Goiânia, v. 8, n. 25, p. 37-39, ago. 1999

9. SERRA, M. C.; GARCIA, P. P. N. S. Delegação de funções: utilização de pessoal auxiliar na clínica odontológica. $\mathbf{R e v}$. ABO Nac., São Paulo, v. 10, n. 2, p. 98-104, abr./maio 2002.

10. SILVA, R. F.; MONINI, A. C.; DARUGE JÚNIOR, E.; FRANCESQUINI JÚNIOR, L.; LENZA, M. A. Utilização de auxiliares odontológicos em Ortodontia - implicações éticas e legais. Rev. Dental Press Ortodon. Ortop. Facial, Maringá, v. 11, n. 5, p. 121-128, set./out. 2006.

11. TOMASSO, S. Atribuições dos auxiliares odontológicos e suas implicações éticas e legais. 2001. Dissertação (Mestrado)-Faculdade de Odontologia, Universidade Estadual de Campinas, Piracicaba, 2001.

Endereço para correspondência

Rhonan Ferreira da Silva

Disciplina de Odontologia Legal FOP-UNICAMP

Avenida Limeira, 901, Bairro Areião

CEP: 13.414-903 - Piracicaba / SP

E-mail: rhonanfs@terra.com.br 